\title{
AVALIAÇÃO DO ÍNDICE DE PLACA VISÍVEL ANTES E DEPOIS DE SESSÕES DE EDUCAÇÃO EM SAÚDE BUCAL COM CRIANÇAS
}

\author{
EVALUATION OF VISIBLE PLATE INDEX BEFORE AND AFTER EDUCATIONAL HEALTH \\ EDUCATION SESSIONS WITH CHILDREN
}

\author{
Marcia de Freitas Oliveira ${ }^{a^{*}}$, Sarita Zanchett ${ }^{b^{*}}$, Andryu Weslley Candido Oliveira ${ }^{c^{*}}$
}

marciaoliveira@furb.bra ${ }^{\mathrm{a}}$, saritazanchett@gmail.com ${ }^{\mathrm{b}}$, andryucandido@hotmail.com ${ }^{\mathrm{c}}$

Universidade Regional de Blumenau (FURB)*

\section{RESUMO}

Data de recebimento do artigo: 05/07/2018

Data de aceite do artigo: 28/05/2019

\begin{abstract}
Introdução: A manutenção de uma boa saúde bucal está diretamente relacionada com a habilidade de um indivíduo controlar a placa bacteriana. Projetos de educação em saúde, principalmente em escolares, tem proporcionado o desenvolvimento de melhores técnicas de escovação e uso de fio dental, tão importantes para dentes hígidos. Objetivo: O objetivo deste trabalho foi avaliar o índice de placa bacteriana em escolares antes e após sessões de educação em saúde bucal na EBM Conselheiro Mafra, Blumenau SC dentro do projeto "FURBmóvel é Saúde e Mais Educação". Materiais e métodos: Foi realizado um levantamento do índice de cárie através do índice de dentes decíduos cariados, extraídos ou obturados (CEO) e do índice de dentes permanentes cariados, perdidos ou obturados (CPOD. Realizou-se também a evidenciação de placa bacteriana e foi anotado o índice de higiene oral simplificado (IHOS). Resultados: Após 4 semanas de educação em saúde bucal, foi realizado novamente o índice de Higiene Oral Simplificado (IHOS). Este trabalho incluiu 44 escolares com média de idade de 5,81 anos. O índice de ceo médio foi 2,54. O índice CPO-D médio foi 0,09. O IHOS médio inicial foi 2,09 e o IHOS médio final foi 1,79. Essa diferença foi significativa segundo o teste $t$ de Student ( $p=0,0203)$. Conclusão: Este trabalho mostrou a eficácia quanto a redução do índice de placa bacteriana em escolares após 4 sessões de educação em saúde bucal.
\end{abstract}

Palavras-chave: Educação em saúde, desenvolvimento infantil, prevenção primária

\section{ABSTRACT}

Introduction: Maintaining good oral health is directly related to an individual's ability to control plaque. Health education projects, especially in schoolchildren, have provided the development of better brushing and flossing techniques, so important for healthy teeth. Objective: The aim of this study was to evaluate the bacterial plaque index in schoolchildren before and after oral health education sessions at EBM Conselheiro Mafra, Blumenau SC within the project "FURBmóvel é Saúde e Mais Educação". Materials and methods: Caries index was obtained through the index of decayed, extracted or obturated deciduous teeth (CEO) and the index of permanent decayed, missing or filled teeth (DMFT). The bacterial plaque was also revealed and the simplified oral hygiene index (IHOS) was recorded. Results: After 4 weeks of education in oral health, the Simplified Oral Hygiene Index (IHOS) was again performed. This study included 44 students with a mean age of 5.81 years. The median ceo index was 2.54. The mean CPO-D index was 0.09. The initial mean IHOS was 2.09 and the final mean IHOS was 1.79. This difference was significant according to the Student $t$ test $(p=0.0203)$. Conclusion: This work showed the efficacy of reducing plaque index in schoolchildren after 4 sessions of oral health education.

Keyword: Health education, child development, primary prevention 


\section{Introdução}

As doenças bucais ainda mais encontradas são a cárie e doença periodontal, e o principal objetivo da odontologia atual é a prevenção destas. $O$ fator etiológico das duas doenças é a tão conhecida placa bacteriana e o biofilme dental, a principal medida de controle ainda é a simples técnica de desorganização e remoção desta por meio de medidas como a escovação dental, utilização de fio dental e dentifrícios fluoretados ${ }^{1}$.

A remoção do biofilme dental em conjunto com a evidenciação de placa realizada sob orientação de um profissional é chamada de escovação dental supervisionada ${ }^{1}$. Esta prática pode ser realizada em pessoas de qualquer idade, no entanto quando feita com crianças em idade escolar os resultados tornam-se ainda melhores pois é um habito que quando adquirido pode perdurar por toda a vida ${ }^{2}$.

A cárie dentaria e a doença periodontal, são problemas de saúde pública e estão relacionadas a outros fatores além daqueles relacionados ao meio bucal de uma pessoa ${ }^{3}$. As doenças bucais são consideradas as mais comuns e predominantes em todo o mundo, sendo que esta condição precária pode ter uma repercussão relevante na qualidade de vida das crianças e adolescentes, sendo capaz de levar a sua saúde geral em decadência ${ }^{4}$.

A OMS ${ }^{5}$ no documento "Promoción de la Salud mediante las Escuelas" adota a relação existente entre educação e saúde; e julga que pode se utilizar este conhecimento para ajudar a formar escolas que melhorem a educação e aumentem o potencial de aprendizagem, melhorando assim a saúde dos escolares, pois a boa saúde auxilia em um aprendizado vantajoso e vice-versa.

Há muito tempo se fala de práticas educativas de promoção em saúde, estas práticas vêm se concretizando com a criação de Escolas Promotoras de Saúde. Este é um projeto que vem sendo utilizado em escolas de alguns países e aos poucos vem sendo implementada em escolas do Brasil. Atualmente as escolas não são apenas um local onde se ensina matérias básicas, mas é também é um ambiente de propagação de informações de temas relevantes que podem transformar a vida dos escolares ${ }^{6}$.

O Projeto de Extensão "FURBmóvel é Saúde e Mais Educação" é da Universidade de Blumenau (FURB) e possuiu como públicoalvo escolares participantes do Programa Federal Mais Educação. Foi proposto pela necessidade de sedimentar práticas de educação em saúde em escolares que permanecem em tempo integral na escola. Este projeto procurou levar noções básicas de saúde bucal, promover ações de promoção e prevenção em saúde.

As ações do projeto ocorreram dentro das salas de aulas e em um veículo fornecido pela Universidade (FURBmóvel) equipado com um consultório odontológico. As atividades clínicas foramaquelesreferentesà atençãobásica evigilância em saúde bucal, capazes de controlar as doenças mais prevalentes, sendo: profilaxia, aplicação de flúor tópico, orientação individual para o controle de placa, tratamento restaurador atraumático (ART), restaurações de baixa complexidade, recontorno e polimento de restaurações, pequenos reparos de próteses, raspagem de cálculo e polimento coronário e diagnóstico de lesões bucais. Como metodologias de educação em saúde destaca-se: grupo focal, rodas de conversa, orientação supervisionada para o autocuidado e controle de placa, jogos e atividades lúdicas.

O objetivo deste trabalho foi avaliar o índice de placa bacteriana em escolares antes e após quatro sessões de educação em saúde bucal no projeto "FURBmóvel é Saúde e Mais Educação" na EBM Conselheiro Mafra.

\section{Metodologia}

Este trabalho incluiu escolares da EBM Conselheiro Mafra do pré-escolar e $1^{\circ}$ ano participantes do Projeto FURBmóvel é Saúde e Mais Educação, cujos pais assinaram o termo de consentimento livre e esclarecido, e os escolares consentiram por meio de um Termo de assentimento para menor (criança): 


\section{TERMO DE CONSENTIMENTO LIVRE E ESCLARECIDO}

1. Identificação do Projeto de Pesquisa

Título do projeto: Pomoção de saúde bucal em escolares no FURBmóvel

Área do conhecimento: Ciências da Saúde

Curso: Odontologia

\begin{tabular}{l|l}
\hline Número de participantes no centro: 120 & Número total de participantes: 120
\end{tabular}

Patrocinador da pesquisa:

Instituição onde será realizada: Escolas Municipais de Blumenau

Nome dos pesquisadores e colaboradores: Profa. Dra. Marcia de Freitas Oliveira

A pessoa abaixo-identificada, que está sob sua responsabilidade, é convidada a participar do projeto de pesquisa acima identificado. Este documento contém todas as informações necessárias sobre a pesquisa que estamos fazendo.
Sua colaboração neste estudo será de muita importância para nós, mas se você ou a pessoa sob sua responsabilidade desistirem a qualquer momento, isso não lhes causará nenhum prejuízo.

2. Identificação do Participante da Pesquisa e do Responsável

\begin{tabular}{|c|c|c|}
\hline \multicolumn{2}{|c|}{ Nome do participante da pesquisa: } & Data de nascimento: \\
\hline \multicolumn{2}{|c|}{ Nome do responsável: } & Data de nascimento: \\
\hline \multicolumn{3}{|c|}{ Vínculo do responsável com o participante da pesquisa: } \\
\hline \multicolumn{2}{|l|}{ Profissão: } & Nacionalidade: \\
\hline Estado civil: & $\mathrm{CPF} / \mathrm{MF}$ : & RG ou RNE: \\
\hline \multicolumn{3}{|l|}{ Endereço: } \\
\hline Telefone: & \multicolumn{2}{|l|}{ E-mail: } \\
\hline
\end{tabular}

3. Identificação do Pesquisador Responsável

Nome: Profa. Dra. Marcia de Freitas Oliveira

Profissão: Professora universitária, cirurgiã- $\quad$ Número do registro no Conselho: CROSC dentista 7250

Endereço: : Rua São Paulo, 2171

Telefone: (047)3321-7324

E-mail: marciaoliveira@furb.br

Eu, responsável pelo menor acima identificado, autorizo sua participação, como voluntário, no presente projeto de pesquisa. Discuti com o pesquisador responsável sobre a minha decisão em autorizar a sua participação e estou ciente de que:

1. O objetivo desta pesquisa é proporcionar aos escolares a promoção em Saúde Bucal por meio de atividades educativas preventivas e restauradoras.
2. Os procedimentos para a coleta de dados serão feitos através de questionários e anamnese. Serão realizados exames clínico e procedimentos de atenção básica em saúde bucal com instrumentos básicos do cirurgião-dentista como espelhos, sonda e pinça, curetas para remoção de cárie, espátula de inserção de material, o qual deve ter duração em torno de 30 minutos. 
3. O benefício esperado é a manutenção e recuperação da saúde bucal após o tratamento, por meio do autocuidado.

4. O desconforto e/ou o risco esperado eventualmente pode ser quanto ao uso da anestesia quando houver necessidade tratamento cirúrgico restaurador.

5. A participação do meu filho (ou do menor sob minha responsabilidade) neste projeto tem como objetivo realizar o tratamento odontológico como também promover e manter a sua saúde bucal.

6. A participação do meu filho (ou do menor sob minha responsabilidade) é isenta de despesas, entretanto tenho ciência de que ele não será remunerado pela sua participação na pesquisa.

7. Meu filho (ou o menor sob minha responsabilidade) tem direito tem direito a assistência, tratamento e indenização por eventuais danos, efeitos colaterais e reações adversas decorrentes da sua participação na presente pesquisa. A assistência ser prestada neste caso será na Clínica de Odontologia da Universidade Regional de Blumenau pelos pesquisadores desta pesquisa.

8. Eu e o participante da pesquisa temos a liberdade de desistir ou de interromper a colaboração do meu filho (ou do menor sob minha responsabilidade) nesta pesquisa a qualquer momento/no momento que desejarmos, sem necessidade de qualquer explicação.
9. Nossa desistência não causará nenhum prejuízo à saúde ou bem-estar físico, social, psicológico, emocional, espiritual e cultural do meu filho (ou do menor sob minha responsabilidade). Nossa desistência não interferirá em futuras assistências prestadas a ele em qualquer instituição ou unidade de saúde.

10. Os dados pessoais do participante da pesquisa serão mantidos em sigilo, mas concordo que sejam divulgados os resultados da pesquisa em publicações científicas, desde que seus dados pessoais não sejam mencionados.

11. Poderei consultar o pesquisador responsável (acima identificado) sempre que entender necessário obter informações ou esclarecimentos sobre o projeto de pesquisa e a participação do meu filho (ou do menor sob minha responsabilidade) na pesquisa.

12. Tenho a garantia de tomar conhecimento, pessoalmente, do(s) resultado(s) parcial(is) e final(is) desta pesquisa.

13. Esta pesquisa foi aprovada pelo Comitê de Ética na Pesquisa em Seres Humanos da FURB (telefone 47 3321-0122).

Declaro que obtive todas as informações necessárias e esclarecimentos quanto às dúvidas por mim apresentadas e, por estar de acordo, assino o presente documento em duas vias de igual teor (conteúdo) e forma, ficando uma delas em minha posse.
( ),

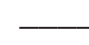

de de

Participante da pesquisa

Profa. Dra. Marcia de Freitas Oliveira

Testemunhas: 
Nome:

RG ou RNE:

$\mathrm{CPF} / \mathrm{MF}$ :

Telefone:
Nome:

RG ou RNE:

$\mathrm{CPF} / \mathrm{MF}$ :

Telefone:

Testemunhas serão exigidas caso o voluntário não possa, por algum motivo, assinar o termo.

\section{TERMO DE ASSENTIMENTO PARA O MENOR (Modelo 1)}

Título da pesquisa: Avaliação do Índice de placa visível antes e depois de SESSÕES DE EDUCAÇAO EM SAÚDE bucal com crianças

Pesquisador e colaboradores: Profa. Dra. Marcia de Freitas Oliveira e Andryu Weslley Candido Oliveira.

Sua mãe/Seu pai, [nome do responsável], autorizou você, [nome da criança], a [falar, responder, brincar...] comigo. E você? Vai querer?

Sim

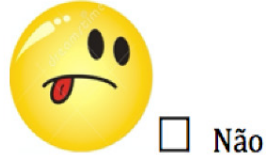

Primeiramente foi realizado um levantamento do índice de cárie através do índice de dentes decíduos cariados, extraídos ou obturados (CEO) e do índice de dentes permanentes cariados, perdidos ou obturados (CPOD).

\section{FURBMÓVEL 2016}

Nome da criança:

Idade:

\section{CPOD/CEO}

$\begin{array}{lllllllllllll} & & 55 & 54 & & 53 & 52 & 51 & 61 & 62 & 63 & 64 & 65 \\ 18 & 17 & 16 & 15 & 14 & 13 & 12 & 11 & 21 & 22 & 23 & 24 & 25\end{array}$

$\begin{array}{lll}26 & 27 & 28\end{array}$

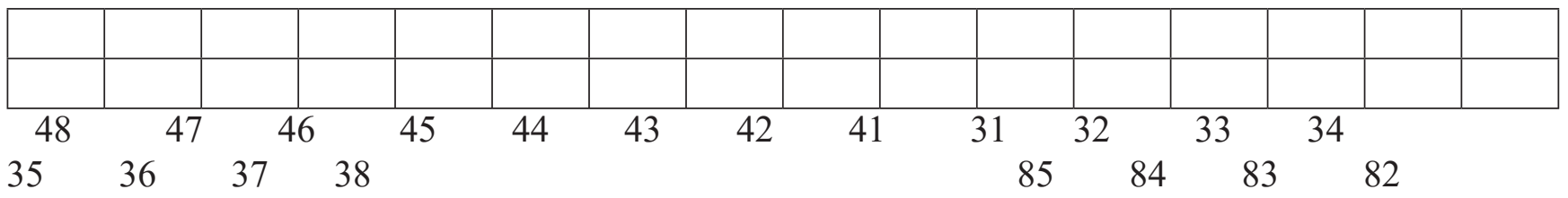

$\begin{array}{llllll}81 & 71 & 72 & 73 & 74 & 75\end{array}$ 
Necessidades odontológicas:

Encaminhamentos:

Lesões bucais: ( ) Sim ( ) Não Quais:

Necessidade de ortodontia:

Problemas sistêmicos:

Radiografia se necessário para diagnóstico:

O exame clínico bucal foi realizado sob luz do refletor odontológico e com os dentes secos e isolados com roletes de algodão dentro do consultório odontológico do FURBmóvel. Após o exame clínico dental, os escolares foram convidados para se dirigirem ao escovódromo, onde foi fornecida uma pastilha evidenciadora de placa bacteriana para cada escolar. Realizou-se então a evidenciação de placa bacteriana e foi anotado o índice de higiene oral simplificado (IHOS) ${ }^{7}$. Foram examinadas as superfícies vestibulares coradas dos dentes 55,51 ,
65, 71 e a superfícies linguais coradas dos dentes 75 e 85 considerando que se havia presença de cálculo ou toda a superfície se encontrava corada recebia escore 3,2/3 da superfície corada escore 2, $1 / 3$ de superfície corada score 1 e se a superfície não se encontrava corada recebia escore 0 . Se o dente a ser examinado não estava presente, era avaliado o dente vizinho, ou se havia presença de dentes permanentes eram examinadas as superfícies vestibulares coradas dos dentes 16,11 , 26,31 e a superfícies linguais coradas dos dentes 36 e 46.

Nome da criança:

Série :

Idade da criança:

Nome dos dentistas:

IHOS

$55 / 16$

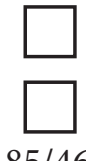

$85 / 46$
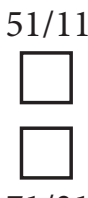

$65 / 26$

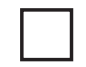

$71 / 31$

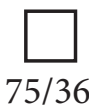

Após o exame, os scores eram somados e divididos pelo número de dentes, sendo que a higiene era classificada de acordo com a média obtida em: de 0 a $0,9=$ bom, de 1 a $1,9=$ regular, de 2 a 2,9 = ruim, 3 = péssimo. Os exames destas superfícies foram realizados em ambiente de luz natural ou quando necessário era utilizado uma lanterna para iluminação. Dois examinadores calibrados paramentados com equipamento de proteção individual básico realizaram os exames e anotaram os índices IHOS.

Em seguida foi realizada orientação em higiene oral, e profilaxia dental.

Um formulário foi utilizado para o armazenamento dos dados das fichas que contem idade, gênero, IHOS, CPOD e ceo.

Nome da criança:

Série :

Idade da criança:

Nome dos dentistas:

IHOS

$55 / 16$
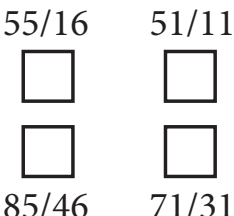

AG

$85 / 46$

$71 / 31$
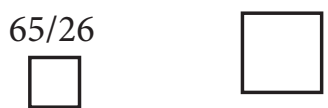
Durante um período de 4 semanas foram realizadas sessões de educação em saúde e atividades de motivação em higiene bucal, tais como escovação supervisionada, utilização de macromodelos, encenações com fantoches com motivos odontológicos, filmes infantis, jogos sobre alimentos cariogênicos e não-cariogênicos, jogos da memória

Figura 1- Demonstração de escovação com macromodelo

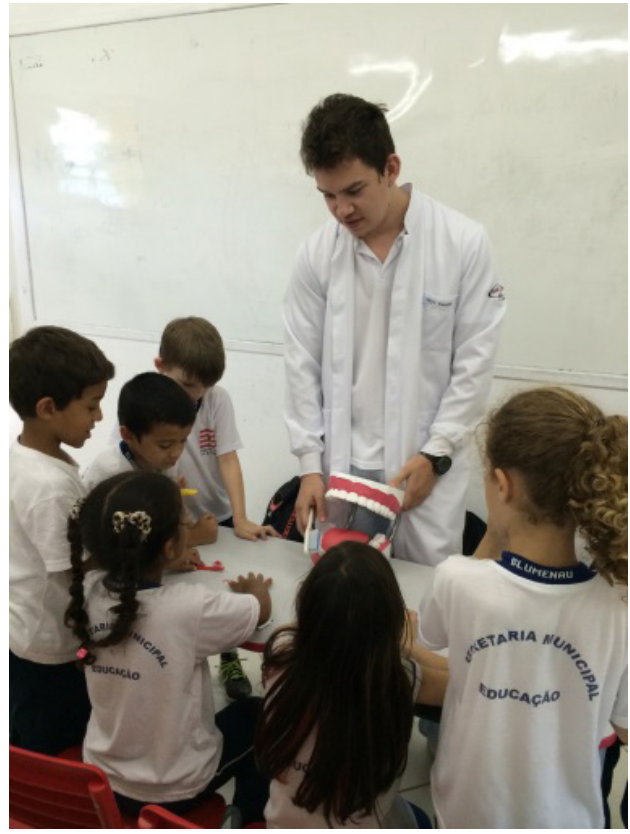

Fonte: autores

Figura 2 -Teatro com fantoches

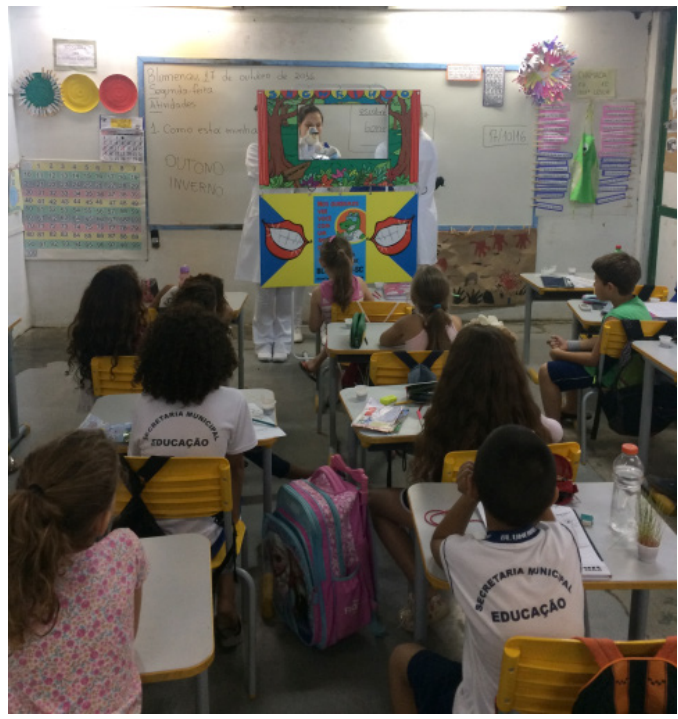

Fonte: autores
Figura 3 - Jogo da memória com motivo odontológico.

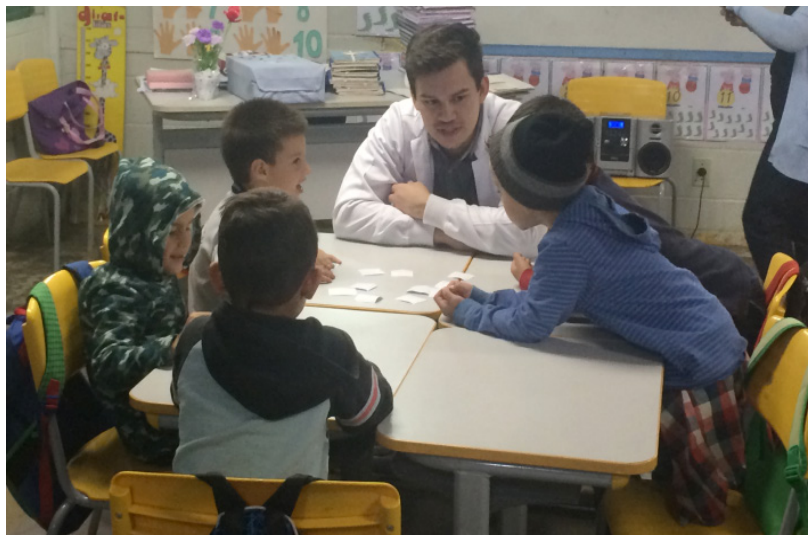

Fonte: autores

Após esse período, as crianças foram convidadas a realizarem novamente o índice de Higiene Oral Simplificado (IHOS) e os exames foram feitos nas mesmas condições de iluminação.

Os dados deste trabalho foram avaliados de forma quantitativa descritiva, por meio de média dos índices IHOS inicial e final, ceo e CPOD.

Para as variáveis qualitativas foi verificada a presença de associação com teste exato de Fisher. Para as variáveis quantitativas foi realizado o teste t de Studant, verificando a diferença entre médias. A distribuição das variáveis foi testada com o teste Shapiro Wilk.

O presente trabalho foi aprovado pelo Comitê de Ética em Pesquisa em Seres Humanos da FURB (processo $\mathrm{n}^{\circ}$ 61683316.5.0000.5370).

\section{Resultados}

Este trabalho incluiu 44 escolares da EBM Conselheiro Mafra, 24 do sexo feminino e 20 do sexo masculino, do pré-escolar e $1^{\circ}$ ano participantes do Projeto FURBmóvel é Saúde e Mais Educação. A média da idade foi 5,81 anos. 
Tabela 1 - Caracterização dos escolares participantes do Projeto FURBmóvel é saúde e Mais Educação

\begin{tabular}{l|l|l}
\hline Variáveis & N & \% \\
\hline Sexo & & \\
\hline Masculino & 20 & 45,4 \\
\hline Feminino & 24 & 54,6 \\
\hline Idade & & \\
\hline $5-6$ anos & 35 & 79,54 \\
\hline$>6$ anos & 9 & 20,46 \\
\hline
\end{tabular}

Fonte: Autores

O índice de ceo médio para os participantes da pesquisa foi 2,54, sendo o menor índice 0 e o maior 11. O índice CPO-D médio foi 0,09, sendo o menor encontrado 0 e o maior 2 .

Tabela 2 - Índice de dentes decíduos cariados, perdidos e obturados (ceo) e índice de dentes permanentes cariados, perdidos e obturados (CPO-D).

\begin{tabular}{l|l|l|l|l}
\hline Variáveis & Média & D. Padrão & mínimo & Máximo \\
\hline ceo & 2,54 & 3.07 & 0 & 11 \\
\hline CPO-D & 0,09 & 0.36 & 0 & 2 \\
\hline
\end{tabular}

Fonte: Autores

Não houve diferença de cpod entre os sexos segundo o teste exato de Fisher $(p=1,00)$.

$O$ índice de higiene oral simplificado médio inicial foi 2,09, considerado um índice de higiene ruim, desvio padrão de 0.39 . O maior índice de higiene oral encontrado foi 2,83 (higiene ruim) e o menor foi 1,5 (higiene oral regular).

$O$ índice de higiene oral simplificado médio final foi 1,79 , considerado um índice de higiene regular, desvio padrão de 0,41 . O maior índice de higiene oral encontrado foi 2,83 (higiene ruim) e o menor foi 1,16 (higiene oral regular).

Essa diferença foi significativa segundo o teste $t$ de Student $(\mathrm{p}=0,0203)$. $\quad \mathrm{E} \quad \mathrm{m}$ relação ao IHOS inicial, não houve diferença de IHOS inicial entre os sexos, verificado pelo teste $t$ de Student ( $\mathrm{p}=0,8893$ ).

Em relação ao IHOS final, não houve diferença de IHOS final entre os sexos, verificado pelo teste $t$ de Student $(\mathrm{p}=0,2684)$.

Em relação ao IHOS final, não houve diferença de ihos final entre as faixas etárias 5 - 6 anos e $>6$ anos, verificado pelo teste $t$ de Student $(\mathrm{p}=0,6345)$.

\section{Discussão}

O uso de indicadores de placa torna-se cada vez mais frequente sendo que mostra a necessidade de cada indivíduo de melhorar ou não sua habilidade de escovação e serve como um avaliador da eficácia em programas de pesquisa ${ }^{8}$.

Neste estudo pode-se observar a redução do índice de placa nos grupos que receberam sessões de educação em saúde realizadas no "Projeto FURBmóvel é Saúde e Mais Educação". O índice de placa mudou de inicial 2,09 para 1,79, indo, portanto, de ruim para regular.

Em um estudo realizado nos centros educativos na cidade Alfenas (MG) também observaram uma redução do índice de placa após 15 sessões de método de escovação indireta com macromodelos e escovação direta supervisionada. Os autores observaram que o índice de placa visível mudou de mau e péssimo para bom e ótimo após o programa de higiene oral ${ }^{9}$

No estudo realizado na clínica multidisciplinar infantil da UNIPAR por meio de fichas clinicas, os autores observaram uma redução no índice de "Bom" de 18,6\% para 25,1\%, "Regular" de 61,3\% para 59\% e "Fraco" de 19,5\% para 15,3\% ${ }^{10 .}$ 
Neste estudo não se observou diferença estatisticamente significativa, tanto no IHOS inicial como no IHOS final quando comparados os diferentes gêneros, masculino e feminino.

A motivação foi fundamental neste estudo para se conseguir este resultado. Foram utilizadas várias estratégias para educação em saúde que entusiasmaram os escolares, sendo que as atividades preferidas eram escovação supervisionada, encenações com fantoches com motivos odontológicos e filmes infantis. Quando as atividades incentivavam uma competição tal como era quando se dividia a sala para colocar em cartazes os alimentos cariogênicos e não cariogênicos, o aprendizado parecia ser facilitado.

A motivação e a educação bucal transmitida na escola têm grande influência sobre a criança. A elaboração de programas de educação e motivação em saúde bucal neste meio é imprescindível para a busca de uma saúde integral ${ }^{11}$.

Os hábitos de higiene bucal são adquiridos na infância, mas quando não incorporados podem ser modificados desde que o cirurgião dentista faça o paciente entender a importância de hábitos adequados e de colocar em prática a sua parte da responsabilidade no cuidado com a saúde bucal ${ }^{12}$.

O ambiente escolar foi um fator importante para o desenvolvimento do projeto, já que nesse tipo de ação em conjunto, além de despertar o interesse individual de cada escolar, há uma interação entre as crianças. $\mathrm{O}$ reconhecimento de si mesmo por meio da visualização do que acontece no seu colega, como é o caso de crianças que possuem cárie e alto índice de placa, servem de exemplo negativo de como desenvolve a doença cárie. Também o inverso acontece, quando a criança não tem cárie e tem baixo índice de placa, serve de estimulo para os demais colegas também cuidarem de sua saúde bucal.

O índice de placa visível e o ceo e cpod registrados neste estudo, serviram para analisar o risco dos escolares à doença cárie no Projeto FURBmóvel. Neste trabalho observou-se que o índice de ceo médio para os participantes da pesquisa foi 2,54, e o índice CPO-D médio foi 0,09. $\mathrm{O}$ índice ceo foi acima do preconizado pela OMS que é de 1,2, no entanto para dentes permanentes ficou abaixo pelo preconizado pela OMS que é 2,6 para 12 anos, que é uma idade superior a idade dos escolares deste estudo.
No Brasil, estudos indicam redução da prevalência e da intensidade da cárie dentária nos últimos anos, graças às ações preventivas e educativas, ao uso de dentifrícios fluoretados e à fluoretação da água de abastecimento ${ }^{13}$.

Programas educativo-preventivos despertam interesse de crianças e contribuem com mudanças efetivas de hábitos e maiores cuidados com a saúde bucal, tornando imprescindível sua aplicação periódica para incentivo e conscientização da necessidade de cuidar da saúde ${ }^{14}$.

\section{Conclusão}

O índice de placa bacteriana em escolares foi reduzido após 4 sessões de educação em saúde bucal no projeto "FURBmóvel é Saúde e Mais Educação". Este trabalho induz a uma reflexão sobre a importância de projetos de educação em saúde bucal na redução e controle da placa bacteriana e consequentemente na cárie dental.

\section{Referências}

1. Gonçalves, 1. et al. Efeitos da escovação supervisionada em estudantes da rede pública de ensino da cidade de Quixadá. Jornada odontológica dos acadêmicos da católica, 2017;2(2):1-5.

2. Frazão, P. Custo-efetividade da escovação dental supervisionada convencional e modificada na prevenção da cárie em molares permanentes de crianças de 5 anos de idade. Caderno de Saúde Pública, 2012; 28(2):281-290.

3. Campos, L. et al. Conhecimento de mães de diferentes classes sociais sobre saúde bucal no município de Cocal do Sul (SC) 1. RSBO, 2010;7(3):287-295.

4. Gambhir, R. S. et al. Impact of school based oral health education programmes in India: a systematic review. Journal of clinical and diagnostic research: JCDR, 2013;7(12):3107.

5. Organização Mundial da Saúde. Available from: http:// www.who.int/eportuguese/publications

6. Piantino, C. B et al. Propostas de ações educativas no ambiente escolar como prática de promoção da saúde. Ciência et Praxis, 2017;9(17):49-52. 
7. Greene, J. G; Vermillion, J. R. The simplified oral hygiene index. The Journal of the American Dental Association, 1964;68(1):7-13.

8. Rovida, T. A. S et al. Controle da placa bacteriana dentária e suas formas de registro. Revista Odontológica de Araçatuba, v. 31, n. 2, p. 57-62, jul/dez 2010.

9. Souza, L.H.T; Gomes, L.T.S; Pessoa, G.S. Controle Do Biofilme Dental E Sangramento Gengival Em Escolares. Revista Eletrônica Acervo Saúde, 2014; 6(1):491-502.

10. Souza, J. G. Avaliação De Higiene Bucal de Crianças Atendidas Na Clínica Odontológica da Universidade Paranaense-Campus Cascavel-PR, Brasil. Arquivos do Museu Dinâmico Interdisciplinar, 2016;20(1):15-24.

11. Valarelli, F. P. et al. Importância dos programas de educação e motivação para saúde bucal em escolas: relato de experiência. Odontologia Clínico-Científica (Online), 2011;10(2):173-176.

12. Kubo, f. M. M; Mialhe, F. L. Fio dental: da dificuldade ao êxito na remoção do biofilme interproximal. Arquivos em Odontologia, 2011;47(1):51-55.

13. Colussi, c. F; calvo, m. C. M. Modelo de avaliação da saúde bucal na atenção básica. Cadernos de Saúde Pública, 2011;27:1731-1745.

14. Ribeiro, D. G; Dovigo, L. N; da Silva, S. R. C. Avaliação de um método educativo em saúde bucal aplicado em escolares de ensino público. Arquivos em Odontologia, 2009;45(3): 154-159.

\section{Como citar este artigo:}

Oliveira MF, Zanchett S, Oliveira AWC. Avaliação do índice de placa visível antes e depois de sessões de educação em saúde bucal com crianças. Rev. Aten. Saúde. 2019;17(60):37-46. 